\title{
STUDI ANALISIS BIOMECHANICS LANGKAH AWALAN (FOOTWORK STEP) OPEN SPIKE DALAM BOLA VOLI TERHADAP POWER OTOT TUNGKAI
}

\author{
Danang Ari Santoso; Edi Irwanto \\ Pendidikan Jasmani Kesehatan dan Rekreasi, \\ Fakultas Olahraga Kesehatan, \\ Universitas PGRI Banyuwangi
}

\begin{abstract}
Biomechanic is one of science field that applied to the sports science to study gestures. This study aims to obtain the number of step prefix (footwork step) in volleyball spike that produces the best power. This research is done by experiment. The number of prefix steps varied are $0,1,2$, and 3 steps. The subjects of the study were volleyball athletes of Universitas PGRI Banyuwangi. Measurement of leg muscle power is done using a highspeed camera. Data processing using kinovea software to obtain data power results. The calculation results show that the more step prefix (footwork step) then the average power tends to increase. Maximum average power occurs in 2 step prefix (footwork step) athlete 4 that is equal to 2340,44 J/dt. Minimum average power occurs at 0 step of the athlete (footwork step) at 1 at 1765,85 J/dt. Maximum power trend occurs in 2 step prefix step. The analysis results also show that 3-step prefixes tend to produce less power than the number of other prefix steps. Spike movement in volleyball is a quick movement in the shortest possible time. This pattern makes an athlete accustomed to using a few prefix steps. The initial step number 3 will cause the speed of athlete's motion to be reduced so as to reduce its power.
\end{abstract}

Keywords: open spike, footwok step, and power

\begin{abstract}
ABSTRAK
Biomechanic adalah bidang ilmu yang diterapkan pada ilmu olahraga untuk mempelajari gerak-gerak tubuh. Penelitian ini bertujuan untuk mendapatkan jumlah langkah awalan (footwork step) dalam spike bola voli yang menghasilkan power terbaik. Penelitian ini dilakukan dengan eksperimen. Jumlah langkah awalan yang divariasi adalah $0,1,2$, dan 3 langkah. Subyek penelitian adalah atlet bola voli Universitas PGRI Banyuwangi. Pengukuran power otot tungkai dilakukan dengan menggunakan high-speed camera. Pengolahan data menggunakan software kinovea untuk mendapatkan data hasil power. Hasil perhitungan menunjukkan bahwa semakin banyak langkah awalan (footwork step) maka power rata-rata cenderung semakin naik. Power rata-rata maksimum terjadi pada 2 langkah awalan (footwork step) atlet 4 yaitu sebesar 2340,44 J/dt. Power rata-rata minimum terjadi pada 0 langkah awalan (footwork step) atlet 1 yaitu sebesar 1765,85 J/dt. Kecenderungan power maksimum terjadi pada langkah awalan sebanyak 2 langkah. Hasil analisis juga menunjukkan bahwa langkah awalan sebanyak 3 langkah cenderung menghasilkan power yang lebih kecil dibanding jumlah langkah awalan yang lain. Gerakan spike dalam bola voli merupakan gerakan yang dilakukan dengan cepat dalam waktu sesingkat mungkin. Pola ini membuat seorang atlet terbiasa menggunakan langkah awalan yang sedikit jumlahnya. Langkah awalan berjumlah 3 akan menyebabkan kecepatan gerak atlet menjadi berkurang sehingga mengurangi powernya.
\end{abstract}

Kata kunci: open spike, langkah awalan (footwork step), dan power 
PENDAHULUAN

Biomekanika adalah ilmu yang menerapkan prinsip-prinsip mekanika terhadap gerak manusia (human movement) pada saat melakukan aktivitas olah-raga (Sunaryadi Y., 2009). Biomekanika juga didefinisikan sebagai bidang ilmu aplikasi mekanika pada sistem biologi. Biomekanika merupakan kombinasi antara disiplin ilmu mekanika terapan dan ilmu-ilmu biologi dan fisiologi. Biomekanika menyangkut tubuh manusia dan hampir semua tubuh makhluk hidup (Jannah F.Z., et al., 2014).

Aplikasi biomekanika di bidang olahraga dilakukan agar dapat menganalisis gerakan-gerakan sehingga hasil analisis ini dapat digunakan untuk memperbaiki teknik secara efektif. Pola gerak yang efektif akan menghasilkan teknik yang baik. Pelatih dapat meng-analisis efisiensi gerakan seorang atlet dan mencoba menentukan apakah atlet dapat melakukan gerakan yang lebih baik (Sunaryadi Y., 2009).
Bola voli merupakan cabang olahra-ga yang banyak digemari oleh kalangan masyarakat pada umumnya. Hal ini dibuk-tikan dengan seringnya kejuaraan yang dilaksanakan di setiap desa. Banyak atlet-atlet junior yang mulai bermunculan dengan adanya kejuaraan tersebut. Sehing-ga menjadi wadah penyaluran bakat di setiap desa yang nantinya akan terus berlanjut untuk berkompetisi demi sebuah prestasi di tingkat yang lebih tinggi.

Dalam permainan bola voli terdapat beberapa teknik seperti passing, blok, service dan spike. Teknik ini berfungsi mematikan lawan untuk mendapatkan point dalam seebuah permainan. Menurut Beutelslahl (dalam Muklis, 2014) spike merupakan suatu cara atau teknik yang mudah untuk memenangkan angka dalam permainan. Sehingga spike merupakan tek-nik yang paling sering digunakan untuk mendapatkan kemenangan dalam permainan bola voli. Spike memiliki beberapa 
metode efektif yang digunakan yaitu tip (spike pelan) dan spike keras (Fergusson dalam Muklis, 2014). Maka dari itu spike merupakan teknik yang paling dominan dibandingkan teknik lainnya dalam permainan bola voli.

Spike dalam permainan bola voli menurut Beutelslahl (dalam Muklis, 2014), memerlukan empat tahapan yang harus dilakukan yaitu awalan, meloncat (take off), memukul (hit), dan mendarat (landing). Pada saat melakukan spike di atas net dibutuhkan power otot tungkai yang baik untuk menunjang dalam pelaksanaan spike.

Olahraga merupakan sebuah keilmuan yang didukung beberapa ilmu seperti psikologi, sosial, fisiologi, anatomi, ilmu gizi, motorik, dan biomekanik. Dengan banyaknya disiplin ilmu yang mendukung, maka dapat digunakan untuk meningkatkan ilmu keolahragaan. Sehingga banyak teknik-teknik yang efektif dalam pelaksanaannya yaitu sebuah gerakan.

\section{Biomekanika di Olahraga}

Olahraga erat kaitannya dengan sebuah gerakan tubuh atau yang dikenal dengan motorik. Proses sebuah gerakan awal dimulai gerakan sederhana atau motorik kasar sampai pada gerakan kombinasi atau motorik halus. Seorang atlet sudah melewati fase tersebut saat usia dini hingga menjadi atlet. Dalam perkembangannya sebuah gerakan bisa menjadi lebih efektif dengan menggunakan prinsipprinsip mekanika.

Biomekanika adalah studi tentang fungsi dan struktural sistem biologi dengan menggunakan metode mekanik. Pendekatan biomekanik terhadap olahraga lebih difokuskan kepada pelaku olahraga (atlet), tetapi pendekatan biomekanik terhadap olahraga juga bisa merambah kepada perilaku objek yang tidak bergerak seperti alas kaki, permukaan (field) dan perleng-kapan olahraga yang dapat mempengaruhi performa atlet.

Dasar-dasar dari biomekanik olahraga adalah ilmu mekanika dan sistem anatomi tubuh manusia. Ilmu mekanika 
sendiri berkaitan erat dengan ilmu hitung, yaitu matematika. Oleh karena itu, pemahaman tentang konsep matematika yang berkaitan dengan ilmu mekanika dan biomekanik sangatlah penting. Konsep matematika tersebut antara lain persamaan matematika sederhana, kalkulus, serta aljabar vektor.

Dengan kemajuan teknologi analisis biomekanik bisa dilakukan dengan bantuan komputer. Analisis biomekanik yang dilakukan menggunakan komputer biasanya dilakukan dengan meneliti hasil rekaman sesi latihan atau pertandingan yang dilakukan oleh atlet. Dari hasil analisis biomekanik, data yang didapat berupa kecepatan atlet, sudut-sudut sendi atlet pada saat berlari. Hasil analisis tersebut yang menentukan apakah atlet sudah memiliki teknik berlari yang baik atau tidak (Perdana A.).

Oleh karena itu betapa pentingnya analisis biomekanika dalam olahraga untuk peningkatan efektifitas sebuah gerakan yang nantinya dapat digunakan seorang pelatih kepada atletnya. Sehingga dengan analisis biomekanika dapat menghasilkan atlet-atlet yang professional demi memajukan olahraga di Indonesia dan mampu bersaing dengan negara lain.

\section{Bola voli}

Bola voli merupakan jenis olahraga bola besar selain bola basket dan sepak bola. Olahraga ini dimainkan oleh enam orang dalam satu timnya. Dalam permainan bola voli terdapat beberapa teknik yaitu service, passing, spike, dan blok. Teknik sangat menentukan dalam permainan bolavoli dan teknik yang paling dominan dalam menghasilkan point adalah spike.

Spike, menurut Beutelslahl (dalam Muklis, 2014) merupakan suatu cara yang mudah untuk memenangkan angka dalam permainan bola voli. Sehingga spike merupakan teknik yang paling sering digunakan untuk mendapatkan kemenangan dalam permainan bola voli. Sedangkan menurut Fergusson (dalam Muklis, 2014) terdapat tiga metode spike yang efektif digunakan yaitu umpan tinggi, Tip (spike pelan) dan 
spike keras. Oleh karena itu dalam permainan bola voli teknik menyerang lebih dominan dibandingkan dengan teknik bertahan. Pada pelaksanaannya teknik spike ini memerlukan awalan sebagai sebuah gerakan terjadinya spike tersebut.

Dalam pelaksanaan spike, menurut Beutelslahl (dalam Muklis, 2014) ada 4 tahapan yaitu awalan, take off (meloncat), hit (memukul), dan landing (mendarat). Sehingga seorang atlet harus menguasai teknik tersebut agar menghasilkan spike yang maksimal untuk mendapatkan point dalam permainan bola voli.

Power

Power merupakan unsur penting yang juga dapat menentukan kemampuan fisik dalam aktivitas yang berat atau kegiatan yang membutuhkan tenaga, seperti lari cepat, meloncat, melompat dan beberapa kegiatan lainnya.

Power merupakan gabungan dari kekuatan dan kecepatan. Seorang atlet dikatakan mempunyai power yang baik jika dapat melakukan aktivitas gerakan kekuat- an dan kecepatan dalam waktu yang bersamaan seperti loncat (take off) dalam spike bola voli. Menurut Sajoto (dalam Ari, 2010) daya ledak (power) adalah kemampuan seseorang mempergunakan kekuatan maksimal yang dikerahkan dalam waktu sependek-pendeknya.

Dari simpulan di atas bahwa power sangat diperlukan sekali pada cabang olahraga lainnya terutama pada cabang bolavoli. Pemain bola voli harus memiliki power otot tungkai yang baik, karena gerakan-gerakan explosive untuk dapat meloncat yang tinggi dengan mengarah ke depan, dan dapat mengembangkan tenaga explosive power yaitu gerakannya sangat berat dilakukan, itu sebabnya adanya pemain melakukan gerakan yang dapat mengembangkan explosive power dengan mengangkat berat badan sebagai beban.

Banyak sekali cabang olahraga yang memerlukan kegiatan meloncat, pada pelaksanaannya seperti cabang olahraga permainan misalnya: bola voli, basket, sepak bola. Dan dalam cabang lain missal- 
nya dalam cabang senam, loncat indah dan lain-lain yang memerlukan tolakan kaki.

\section{METODE PENELITIAN}

Penelitian ini akan dilakukan di laboratorium olahraga Universitas PGRI Banyuwangi. Sampel penelitian diambil sejumlah satu atlet bola voli dari mahasiswa Prodi Olahraga Kesehatan dan Rekreasi Universitas PGRI Banyuwangi. Penelitian dilakukan dengan cara pengamatan atau perekaman gerak para atlet menggunakan kamera handycam. Atlet akan melakukan gerakan spike dengan awalan $0,1,2$, dan 3 langkah dengan masing-masing awalan langkah 5 kali ulangan. Hasil pengamatan akan dilakukan pengolahan data sehingga didapat foto untuk mendapatkan langkah awalan yang efektif dalam menghasilkan power otot tungkai.

Data gerakan spike dengan awalan didapat dengan kamera handycam. Atlet di posisikan dengan jarak sesuai dengan jumlah awalan. Atlet melakukan gerakan spike dengan awalan yang sudah ditentukan. Posisi bola digantung pada ketinggian 290 cm dari permukaan lantai.

Rekaman kamera handycam berupa rekaman video diolah menggunakan software untuk mendapatkan foto-foto gerak. Foto-foto ini merupakan hasil capture video dan dijadikan gambar frame by frame. Masing-masing gerak atlet diambil satu foto sehingga dengan 5 kali ulangan gerak akan didapat 5 foto dalam setiap awalan. Foto-foto ini selanjutnya dianalisis dengan software Kinovea untuk mendapatkan perubahan waktu dalam gerakan awalan, perubahan jarak dan tinggi loncatan. Hasil pengukuran ini akan dihitung nilai rata-ratanya.

\section{HASIL PENELITIAN DAN}

\section{PEMBAHASAN}

\section{Hasil Penelitian}

Data hasil penelitian bedasarkan waktu pengambilan data dihitung nilai rata-ratanya sehingga didapat hasil perhitungan dalam tabel 1. 
Tabel 1. Data Power (J/dt)

\begin{tabular}{ccccc}
\hline $\begin{array}{c}\text { Footwork } \\
\text { Step }\end{array}$ & \multicolumn{4}{c}{ Power rata-rata (J/dt) } \\
\hline 0 & 1765,85 & 1755,91 & 2176,71 & 1980,90 \\
\hline 1 & 2002,52 & 1899,07 & 2231,68 & 2004,60 \\
\hline 2 & 2112,38 & 1836,09 & 2284,40 & 2340,33 \\
\hline 3 & 2085,43 & 1634,09 & 2224,17 & 2127,71 \\
\hline
\end{tabular}

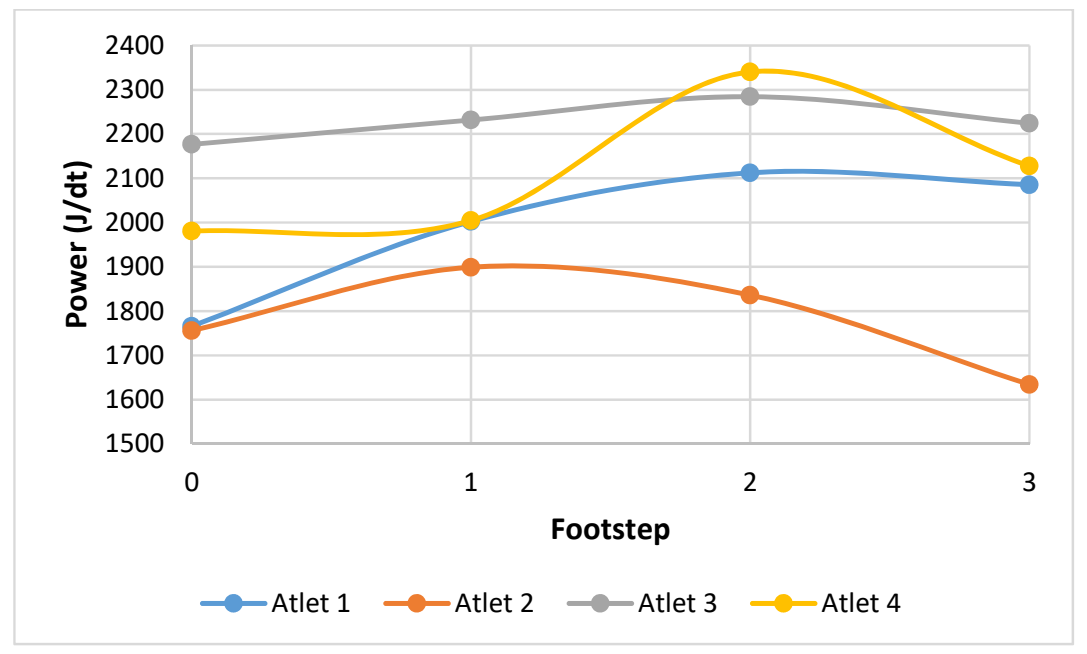

Gambar 1. Grafik Data Power (J/dt)

\section{Pembahasan}

Pada gambar 1, dapat dilihat mengenai grafik data power, dari grafik tersebut hasil perhitungan menunjukkan ba-hwa semakin banyak langkah awalan (footwork step) maka power rata-rata cenderung semakin naik. Grafik hasil penelitian juga menunjukkan bahwa power rata-rata maksimum terjadi pada 2 langkah awalan (footwork step) atlet 4 yaitu sebesar 2340,44 J/dt. Power rata-rata minimum terjadi pada 0 langkah awalan (footwork step) atlet 1 yaitu sebesar 1765,85 J/dt.

Grafik penelitian pada gambar 5 juga menunjukkan bahwa kecenderungan power maksimum terjadi pada langkah awalan sebanyak 2 langkah. Tetapi atlet 2 menunjukkan pola yang berbeda dimana power maksimum terjadi pada langkah awalan sebanyak 1 langkah. Perbedaan ini disebabkan karena spesialis atlet 2 yang menjadi subyek penelitian adalah atlet yang kompetensinya quicker (bola pendek) 
sehingga atlet 2 memiliki power maksimal pada langkah awalan (footwork step) 1 dan mengalami penurunan pada langkah awalan (footwork step) 2.

Grafik juga menunjukkan bahwa langkah awalan sebanyak 3 langkah cenderung menghasilkan power yang lebih kecil dibanding jumlah langkah awalan yang lain. Gerakan smash dalam bola voli merupakan gerakan yang dilakukan dengan cepat dalam waktu sesingkat mungkin. Pola ini membuat seorang atlet terbiasa menggunakan langkah awalan yang sedikit jumlahnya. Langkah awalan berjumlah 3 akan menyebabkan kecepatan gerak atlet menjadi berkurang sehingga mengurangi powernya.

Power lompatan merupakan hasil kali gaya dan kecepatan. Gaya dalam hal ini adalah gaya tubuh yang tergantung pada masa $(\mathrm{kg})$ dan konstanta gravitasi $\left(\mathrm{m} / \mathrm{dt}^{2}\right)$. Kecepatan dalam hal ini dibagi 2 yaitu kecepatan langkah (footstep) dan kecepatan lompat. Kecepatan langkah merupakan jarak langkah dibagi waktu tempuh.
Kecepatan lompat merupakan tinggi lompatan dibagi waktu lompatan.

Hasil pengolahan data menunjukkan bahwa power lompatan telah sesuai dengan teori yang menjelaskan perbedaan power terjadi karena perbedaan tinggi dan waktu lompatan. Langkah awal (footstep) merupakan energi awal yang memicu atau mempengaruhi gerak lompat atlet. Kecepatan langkah awal akan mempengaruhi power untuk melompat. Hal ini menyebabkan perbedaan dalam tinggi dan waktu lompatan sehingga berpengaruh terhadap hasil power lompatan.

\section{KESIMPULAN}

Berdasarkan pembahasan maka dapat diambil kesimpulan sebagai berikut:

1. Semakin banyak langkah awalan maka power yang dihasilkan cenderung sema-kin meningkat.

2. Power minimun terjadi pada langkah awalan (footwork step) 0 sedangkan power maksimun terjadi pada langkah awalan (footwork step) 2. 
3. Data hasil penelitian menunjukkan rata-rata pada langkah awalan 3 cenderung menurun, hal ini disebabkan kecepatan gerak atlet menjadi menurun.

\section{DAFTAR PUSTAKA}

Hussain, I. (2013). Videographical Analysis of Arm Swing on Spike Jump Performance of Two Different Functional Classes' Volleyball Players. European Academic Research, vol. I, issue 6/ Sepember 2013, ISSN 2286-4822.

Jannah F.Z, Perdana A, Nurhasanah S, Suryano N, Jutalo YH, Budi AS. (2014). Analisis Biomekanika Dalam Gerakan Dasar Anggar. Jakarta: Universitas Negeri Jakarta

Kartikaningtyas, E. (2011). Pengaruh Metode Latihan Quick Smash Dengan Awalan Dan Tanpa Awalan Terhadap Hasil Quick Smash Dalam Permainan Bola voli Pada Atlet Putra Klub Porvit. Skripsi. Universitas Negeri Semarang.

Kurnianto, A. (2013). Analisis Teknik Smash Atlet Bola voli Junior Ganevo Yogyakarta. Skripsi. Universitas Negeri Yogyakarta.

Muklis. (2014). Survey Smash Dalam Kejuaraan Bola Voli Forsa Cup Putri Tahun 2014 / 2015 Di Desa Doko Kecamatan Ngasem Kabupaten Kediri. Skripsi. Universitas Nusantara PGRI Kediri.
Perdana A. Aplikasi Analisis Biomekanik Untuk Mengembangkan Kemampuan Belari Atlet Lari. Jurusan Teknik Informatika, Fakultas Teknologi Industri, Universitas Gunadarma. Depok.

Prasetya A.D, Waluyo M, Sumartiningsih S. (2012). Analisis Kinesiologi Teknik Keterampilan Tubuh Pada Olahraga Lempar Lembing. Journal of Sport Sciences and Fitness 1(2): $1-7$.

Purwanto, D dan dkk. (2012). Survey Kondisi Fisik dan Keterampilan Teknik Dasar Bola voli pada Klub Bola voli Putri Bravo Banjarnegara. Journal of Physical Education, Sport, Health and Recreation 2 (4) (2013).

Santoso, D.A. (2010). Pengaruh Latihan Plyometric Split Squat Jump Dan Depth Jump Terhadap Power Otot Tungkai Pada Pemain Bola voli Sma Negeri 1 Panarukan Kabupaten Situbondo.

Saputra, R. (2013). Pengaruh Modifikasi Latihan Lompat Balok dan Latihan Bola Gantung Terhadap Kemampuan Smash Dalam Permainan Bola voli pada Siswa SMA Negeri 6 Kota Jambi. Skripsi. Universitas Jambi.

Sunaryadi Y. (2009). Aplikasi Biomekanika Dalam Pelatihan Yudo. Penataran Pelatih Yudo Nasional. Ciloto. Jawa Barat.

Taryono. (2010). Kontribusi Kekuatan Otot Tungkai dan Kekuatan Otot Lengan Terhadap Hasil Pukulan Spike dalam Permainan Bola voli. Motion Volume 1 No. 1 September 2010. 